\title{
Política de Defesa é uma Política de Governo
}

\author{
Defense Policy is a government policy
}

GUNTHER RUDZIT* GUILHERME STOLLE PAIXÃO E CASARÕES***

\section{INTRODUÇÃO}

Políticas públicas são políticas de Estado ou de governo? No Brasil, esse entendimento ganhou força ao longo do século $\mathrm{XX}$, ao redor de duas áreas em particular: a política externa (Lima, 2000) e a política de defesa. Isso explica não somente a importância que suas burocracias específicas - respectivamente, o Ministério das Relações Exteriores (MRE) e os ministérios militares, hoje centralizados no Ministério da Defesa (MD) - assumiram ao longo do tempo, mas também ilumina o fato de serem carreiras sólidas e bastante fechadas a influências do mundo político. Mesmo que nenhum destes ministérios assuma oficialmente o insulamento de suas áreas temáticas, já que são constitucionalmente vinculados aos interesses do Poder Executivo, parece-nos claro que a concepção de política de Estado orienta seus formuladores.

Tomemos o caso da área militar, corporificada no MD. Apesar de nada constar nos documentos públicos, os discursos caminham na direção que a política de defesa não deve ser influenciada pelas peculiaridades ideológicas do governo do momento, uma vez que se trata de uma questão existencial. Recentemente, o Diretor do Instituto Pandiá

\footnotetext{
* Doutor em Ciência Política (USP). Professor e Coordenador do curso de graduação e pós-graduação em Relações Internacionais das Faculdades Rio Branco. E-mail: grudzit@yahoo.com.

** Doutor em Ciência Política (USP). Professor de Relações Internacionais da Fundação Getúlio Vargas, das Faculdades Integradas Rio Branco e da ESPM. E-mail: casaroes@gmail.com.
} 
RBED, v. 2, no 1, jan./jun. 2015

Calógeras, braço intelectual do Ministério da Defesa, fez a seguinte afirmação: "[p]olítica de defesa é uma política de Estado, não é uma política de governo - não é uma opção" (Rocha, 2014: s/p).

Tal afirmação sugere, seguindo o corolário realista, que a sobrevivência coletiva - objetivo último do Estado - não pode ser relativizada a partir de filtros ideológicos ou partidários. Esta linha de pensamento, desenvolvida principalmente a partir dos trabalhos de Edward H. Carr, Hans Morgenthau e Kenneth N. Waltz, ganhou força durante a Guerra Fria, quando a lógica da guerra termonuclear e a disputa entre as duas superpotências dominava a política internacional, o que gerou, em certos momentos, o temor real da extinção de alguns Estados. É com vistas à sobrevivência que o realismo sugere que a política de defesa seja pensada de maneira contínua, linear, motivada precipuamente pelas ameaças externas que se coloquem às entidades estatais. Em outras palavras, o interesse nacional mais básico é a garantia da segurança do Estado - e, por extensão lógica, de seus cidadãos. Não há, portanto, opção.

Por outro lado, contrapõe-se ao corolário realista a noção que a política de defesa, assim como outras políticas públicas, deve ser regularmente submetida ao crivo popular, especialmente em regimes democráticos. Esta visão trata a segurança do Estado não como um objetivo coerente e linear, sendo sempre filtrada pela realidade interna do país e pelas dinâmicas político-partidárias que se colocam nas conjunturas históricas específicas. Neste caso, a política de defesa seria fruto, justamente, de uma diversidade de opções: caminhos que se abrem no contexto do processo decisório, colocados à mesa sempre que o país enfrenta desafios internos ou externos, e cuja resultante é decorrência da correlação de forças dos atores políticos num determinado momento.

É essa segunda visão que sustenta o argumento do presente artigo. Defendemos que a política de defesa no Brasil pode e deve ser concebida como política de governo, por duas razões fundamentais: em primeiro lugar, é através dela que se dá o controle civil sobre os meios militares. Isto é fundamental, dada a história recente brasileira, uma vez que reforça nosso princípio democrático. Em segundo lugar, submeter a política de defesa à lógica de governo permite que se realizem eventuais mudanças, correções de rumo e adaptações frente a novas realidades políticas e estratégicas, tanto internas quanto externas. É a interpretação governamental sobre os imperativos de defesa que constitui, no limite, a definição do chamado interesse nacional. 
A defesa do nosso argumento será realizada a partir de elementos teóricos e empíricos, sobre os quais se estruturará o texto. Na próxima seção, faremos uma revisão da literatura sobre defesa, mostrando os caminhos conceituais sobre os quais se constrói a ideia de que a política de defesa, em contextos democráticos, é política de governo. Em seguida, faremos um estudo de caso sobre os Estados Unidos ao longo da Guerra Fria, com vistas a mostrar que, mesmo em contextos em que havia uma clara ameaça existencial externa, a política de defesa - contrariamente aos princípios realistas - foi submetida aos filtros políticos, burocráticos e partidários. Por fim, uma seção conclusiva buscará sintetizar a discussão, transcendendo o exemplo norte-americano e olhando especificamente para o caso brasileiro.

\section{POLÍTICA DE DEFESA COMO POLÍTICA DE GOVERNO: UMA AVALIAÇÃO DA LITERATURA VIGENTE}

Uma contraposição a esta visão no planejamento militar começa a surgir já durante a Guerra Fria, uma vez que esta se dá fundamentalmente baseada na perspectiva das grandes e superpotências. Kolodziej e Harhavy (1982) desenvolveram seu modelo de formulação de uma política de segurança para países em desenvolvimento no qual leva em consideração não só a realidade externa, mas também a interna, como composição da população, tipo de desenvolvimento econômico e estrutura governamental e regime político. Consequentemente, uma política de segurança ou de defesa precisaria levar em consideração estes aspectos, que, tradicionalmente, o realismo não o faz.

Um autor que coloca muito bem que uma política de segurança nacional ou de defesa é fruto de uma dinâmica política interna aos Estados é Buzan (1991). Segundo este autor, há vários interessados diretamente na elaboração desta política, fazendo com que esta não seja somente um produto entre um Estado e o ambiente internacional. Para Buzan, meios de comunicação, partidos políticos, diferentes órgãos burocráticos do governo, setor privado e mesmo a própria população de um país procuram influenciar no processo decisório de formulação desta política pública. Por isto mesmo ele diz que

Snational security policy is disconnected from a rationality of the external security problem not only by domestic intrusions into the policy process, but also by a political market in which even distorted policy may get 
RBED, v. 2, no 1, jan./jun. 2015

bumped or altered while interacting with other policies competing for the state attention and resources. (Buzan, 1991: 355)

Por isto mesmo, tendo em vista que todas essas variáveis são mutáveis, são os governos eleitos - e, mesmo em menor peso, os não eleitos - que têm que decidir quais as recursos serão destinados à defesa, resultando em uma política que altera conforme as condições se alteram. Contudo, em nenhum momento não se admite que o objetivo maior não seja a sobrevivência do Estado.

Outro argumento contra a análise baseada nas unidades básicas estatais é a de Allison e Zelikow (1999), na qual defendem que as ações governamentais são políticas resultantes de um processo político interno, destacando:

National behavior in international affairs can be conceived of as something that from intricate and subtle, simultaneous, overlapping and often deadly serious games among players located in positions in a government. The hierarchical arrangement of the players constitutes the government. (Allison; Zelokow, 1999: 295)

Justamente a constituição de um governo democrático é a segunda questão que a afirmação que uma política de defesa é uma política de Estado levanta, ou seja, o cerne de uma democracia. Esta percepção defenderia o insulamento burocrático das forças armadas, como que se este ramo do governo não estivesse subordinado à vontade da liderança política eleita. Esta visão vai contra toda a literatura internacional acerca desta relação, pois não se pode esquecer que uma democracia requer que forças armadas, assim como os outros setores não eleitos do Executivo, sejam subordinadas aos funcionários eleitos. Zagorski (1992) aponta muito bem que a moderna teoria democrática dá a fórmula para se estabelecer tal controle sobre os meios militares e outros setores, ou seja, um único chefe executivo controla a máquina burocrática governamental, a qual, por sua vez, é governada por normas legais e burocráticas. Assim, ao chefe executivo cabe designar os objetivos políticos e seus auxiliares políticos elaborarem as políticas, enquanto à burocracia - tanto civil quanto militar - é suposta a execução ou administração das políticas para se alcançar tais objetivos. Esta burocracia deve ser organizada e recrutada em bases de competência técnica nos diversos campos administrativos, ou seja, este sistema pressupõe que os militares estejam sob a supervisão dos civis e a mando da Lei. Contudo, Zagorski faz a ressalva que as forças armadas não deveriam ser excluídas 
das discussões das políticas públicas que tenham pretensões justas de oferecer opinião técnica.

Nesta mesma linha, mas com uma visão diferente, Cottey, Edmunds e Forster (Cottey et al, 2002) defendem que a expressão controle civil sobre os meios militares não seja a mais adequada, pois traz a ideia de que esta relação seria, necessariamente, de confrontação. Assim, eles defendem que se deveria falar em governança democrática dos setores de segurança e defesa, com o reconhecimento, tanto de civis quanto de militares, que a melhor maneira de gerir os temas afeitos só é possível pelo controle democrático representado na figura do governo democraticamente eleito.

É nesta mesma linha que Alsina Júnior (1999) coloca o problema brasileiro na relação entre nossa democracia e a política de defesa. Considerado aqui praticamente um domínio do Executivo, uma vez que há poucos incentivos à participação do Legislativo nesta área, mesmo assim este Poder acaba por não controlar efetivamente o setor militar, uma vez que há pouco a lucrar politicamente na condução da área, levando a condução da mesma aos próprios militares. Isto faz com que "a política de defesa nacional seja fortemente condicionada pela dinâmica inercial das ações das três forças singulares" (Alsina Júnior, 1999: 77), ou seja, o axioma básico de defesa é fundamentalmente conduzido pela lógica interna, e não externa.

Um ponto importante ainda que cabe destacar neste debate, e que pode ajudar a dirimir alguns desentendimentos, é a diferenciação que Couto e Arantes (2006) fazem em discussão correlata entre normas constitucionais (Estado) de políticas públicas (governo). Os autores distinguem muito bem três conceitos, quais sejam, polity, politics e policy.

Definimos em inglês as três dimensões da política em decorrência da falta de termos apropriados e claramente diferenciados na língua portuguesa para cada uma delas. Sumarizando, a polity corresponde à estrutura paramétrica estável da política e que, supõe-se, deve ser a mais consensual possível entre os atores; a politics é o próprio jogo político, a policy diz respeito às políticas públicas, ao resultado do jogo disputado de acordo com as regras vigentes. (Couto; Arantes, 2006 : 47)

Esta separação vai de encontro com a definição que Proença Jr. e Diniz (1998) já haviam elaborado sobre o que é uma política de defesa. Para os autores, uma política de defesa é como qualquer outra, na qual ela é o resultado da "relação de força e interesses políticos predominantes no momento da tomada decisão” (Proença Jr. e Diniz, 1998: 47), fazendo com que ela seja "provisória, temporária e seus objetivos tenderão a oscilar conforme o 
grau de diferença entre os grupos e suas respectivas posições de força no cenário político.” (Proença Jr. e Diniz, 1998: 37) Eles destacam ainda esta realidade ao lembrar que, mesmo em tempos de guerra, esta não toma caráter "puramente militar", uma vez que o emprego militar, apesar te aspectos estratégicos e táticos, é essencialmente político, como defendido por Clausewitz em Da Guerra. Nesta mesma linha, Rudzit e Nogami (2010) defendem que são as condicionantes políticas que transformam as percepções de ameaça em objetivos de segurança nacional e de defesa, uma vez que esse processo precisa ser entendido como sendo explicitamente no sentido político.

Esta dinâmica pode ser observada nas democracias mais antigas e estruturadas, dentre elas, sem dúvida alguma, estão os Estados Unidos, e por três motivos. O primeiro é que, mesmo no decorrer da Guerra Fria, o período no qual houve um consenso tanto sobre a do sistema americano (polity) quanto em relação ao que era o interesse nacional, sua política militar (policy) mudou conforme as realidades políticas interna e externa se modificavam. O segundo motivo se refere ao papel que o Legislativo americano tem na elaboração das políticas de segurança e defesa, que Alsina Junior (2009) destaca como sendo pequeno e um domínio primordialmente do chefe de Estado. Mas, mesmo assim, no final deste longo período de confronto, o Congresso impôs mudanças que levaram à distinção entre segurança e defesa e grandes transformações no escopo das políticas de defesa deste país deste momento em diante. E, terceiro, esse conflito foi o que, pela primeira vez, colocou em risco a existência do Estado, e nem por isto a liderança política americana deixou de fazer mudanças na política de defesa em decorrência da sua percepção e interpretação de como alcançar a sobrevivência do país.

Assim, se uma política de defesa fosse o reflexo da capacidade militar de cada Estado, ou da distribuição de poder no sistema internacional, durante a Guerra Fria, a tendência seria da política americana praticamente não mudar, uma vez que este país tinha uma superioridade militar quase incontestável frente à URSS até o início dos anos 1970. Contudo, não foi isto que ocorreu, houve mudanças de postura estratégica bastante acentuadas ao longo de todo este conflito, indicando que fatores internos devem ter influenciado neste processo decisório. Além do mais, este país se destaca também por ser um referencial importante em termos de democracia e relação civil-militar. Contudo, devido ao espaço disponível, não se aprofundará nas mudanças internas ocorridas. 


\section{GUERRA FRIA E AS POLÍTICAS DE SEGURANÇA NACIONAL NOS EUA}

Desde a criação da Constituição americana, os chamados pais fundadores se preocupavam com o aspecto do controle civil sobre os meios militares. Em grande parte, este fato se deve pela tradição britânica de haver este controle pelo Parlamento, que, após a longa guerra civil inglesa, conseguiu impor uma legislação, conhecida como Mutiny $A c t^{1}$, na qual se estabeleceu seu controle sobre os militares (Mallinson, 2009). Além disto, os americanos tinham uma visão que milícias locais seriam mais eficientes que um exército permanente, principalmente que, para eles, a existência de forças militares poderiam favorecer um tirano a tomar o poder (Kohn, 1975).

Desde a fundação dos Estados Unidos, as forças armadas continuaram organizadas praticamente da mesma forma. Foi somente em setembro de 1947 que houve a primeira grande mudança, quando foi aprovado o $\mathrm{Na}$ tional Security Act of 1947, que reestruturou os órgãos militar e de Inteligência. Esta reorganização criou o Departamento de Defesa (Department of Defense - DoD, em inglês), que, inicialmente, foi chamado de National Military Establishment e só foi modificado para DoD por uma emenda em 1949. Este Ato teve fundamental importância, pois subordinou os comandantes militares ao comando do Secretário de Defesa, estabeleceu o Comando do Estado Maior Conjunto (Joint Chiefs of Staff - JCS, em inglês), criou a Agência Central de Inteligência (Central Intelligence Agency - CIA, em inglês) assim como o Conselho de Segurança Nacional (National Security Council - NSC, em inglês), como o órgão coordenador central para a política de Segurança Nacional do poder Executivo (Cambone, 1998).

Desde há muito se discutia nos Estados Unidos a necessidade de criação de uma estrutura militar comum a fim de melhorar a coordenação civil-militar, sendo que só algumas modificações haviam sido implementadas no governo de Woodrow Wilson, mas com poucos efeitos. O grande problema era conseguir um consenso, mesmo após a Segunda Guerra Mundial, uma vez que havia quatro pontos que criavam divergências na liderança política do país (Cambone, 1998): (1) os papéis e missões de cada uma das forças, importante para definições de doutrina, estrutura de força e orçamento; (2) o papel do JCS, pois o medo dele concentrar força demasiada, como foi no Estado Maior Conjunto da Prússia do século XIX, ameaçaria o controle civil; (3) se um militar da ativa poderia ser o diretor geral da CIA; e (4) quais os poderes que a CIA teria, pois havia o medo desta agência se tornar uma Gestapo ${ }^{2}$. Superadas estas questões, foi com esta estrutura que os EUA 
enfrentaram a longa Guerra Fria e as suas implicações para a segurança nacional americana.

Apesar da histórica desconfiança sobre as forças armadas, a constituição do Pentágono e da importância que elas passaram a ter no contexto da Guerra Fria, o efetivo controle civil sobre os meios militares ficou muito claro nos EUA. No trabalho mais antigo sobre o tema, Jordan, Taylor, Meese e Nielsen (2009) ${ }^{3}$ analisam como cada presidente americano deste período procurou lidar com o setor militar, e traçam as grandes mudanças nas políticas que os seis presidentes implementaram.

O governo de Harry S. Truman (1945-1953) foi importante por conseguir reverter a tendência isolacionista de boa parte da sociedade americana e forjar a estrutura militar com a qual contariam ao longo da Guerra Fria. Apesar de sair da Segunda Guerra com uma estrutura militar presente em todo o globo, como a única potência nuclear, território e economia intocados e líder absoluto em tecnologia, a pressão doméstica para a desmobilização foi muito grande. Esse grande processo de desarmamento ocorreu mesmo quando a aliança com a União Soviética começava rapidamente dar lugar ao aumento da tensão na Europa Oriental, Grécia, Irã, Turquia e Extremo Oriente. A mudança veio com o discurso do presidente perante o Congresso em 12 de março de 1947, e a proposta de Contenção do comunismo, e que ficou conhecida como Doutrina Truman, levando ao abandono da tradição de forças armadas pequenas. Isto se deu uma vez que, a fim de negar a habilidade de expansão soviética, implicava na necessidade de forças prontas para agir a qualquer hora, uma vez que a superioridade atômica americana não seria suficiente para conter um avanço do Exército Vermelho sobre a Europa Ocidental, e muito menos contra a integridade territorial do Irã, como destacou o Secretário de Defesa da época, James Forrestal (Jordan et al, 2009).

Foram duas ações soviéticas que ajudaram a administração Truman a conseguir o apoio do Congresso e aumentar os gastos para ter uma presença militar no exterior. A contínua pressão e mudanças ocorridas na Europa ocupada pela URSS levou à criação da Organização do Tratado do Atlântico Norte (OTAN), em 1949, instituindo um plano de chegar a noventa divisões no total (metade na ativa e metade na reserva) até o ano de 1954, sendo que os americanos seriam responsáveis por metade deste total ${ }^{4}$. A segunda ação soviética que contribuiu com a administração Truman foi a Guerra da Coreia, levando a um aumento de $26 \%$ nos gastos militares em três anos, baseados em três premissas: (1) ganhar a guerra na península co- 
reana; (2) criação de uma base mobilizável no longo prazo; e (3) desenvolvimento de forças ativas, a fim de equilibrar a capacidade soviética e deter agressões futuras destes. Assim, este governo conseguiu que a população e o Congresso aceitassem a necessidade de intervenções externas e a manutenção de forças armadas grandes em tempos de paz.

Ainda segundo Jordan et al (2009), a administração Dwight Eisenhower (1953-1961) assumiu com o desafio de conciliar as demandas por maiores gastos militares com as crescentes necessidades internas. A fim de manter a vitalidade da economia americana, o presidente tinha como objetivo reduzir os gastos militares e equilibrar o orçamento federal, o que levou a um impasse com o JCS, que apoiava um grande rearmamento, como planejado anteriormente. Somente com a troca da liderança militar, em maio de 1953, que foi possível para o governo implementar seu plano baseado na crença que as armas nucleares teriam papel decisivo na contenção soviética, juntamente com o poder aéreo estratégico e a expansão da capacidade de defesa do território continental dos Estados Unidos de ataques aéreos. Este planejamento ficou conhecido como a Política de Retaliação Maciça, na qual qualquer avanço soviético na Europa ou algum outro aliado seria enfrentado por um ataque nuclear em larga escala.

Ainda segundo os autores, as administrações Kennedy-Johnson (19611969) implementaram uma profunda mudança no planejamento militar dos EUA. Com o crescimento do arsenal nuclear estratégico soviético, ficou claro que a ameaça de retaliação maciça não fazia mais sentido, levando o então secretario de defesa Robert McNamara a desenvolver a Política da Resposta Flexível, que consistiu na manutenção de uma dissuasão nuclear crível através da capacidade de um segundo ataque retaliatório ${ }^{5}$ baseado em submarinos, porém, desenvolvendo uma capacidade convencional flexível.

Esta realidade convencional se deveu ao alastramento de pequenas guerras e crises ao redor do mundo que colocaram em xeque a doutrina de retaliação maciça. Assim, as forças armadas passaram a seguir o planejamento para uma postura de duas guerras e meia, ou seja, uma guerra em larga escala na Europa, uma outra equivalente em outro lugar do mundo e um terceiro conflito menor em algum outro teatro. Essa capacidade foi desenhada para cobrir as necessidades como as intervenções na República Dominicana e no Vietnã, em meados dos anos 1960.

Uma nova mudança veio com as administrações Richard Nixon e Gerald Ford (1969-1977), ainda segundo Jordan et al (2009). Com a paridade estratégica conseguida pela União Soviética e sua capacidade de segundo 
ataque, a política nuclear americana deixou de perseguir a superioridade nuclear pela política da Suficiência Estratégica ${ }^{6}$. Esta nova política era baseada na destruição certa ${ }^{7}$ via tripé nuclear: mísseis balísticos intercontinentais baseados em terra (ICBM, em inglês), mísseis balísticos intercontinentais lançados de submarinos (SLBM, em inglês) e bombardeiros estratégicos tripulados, o que garantiria danos irreparáveis ao inimigo pela destruição de suas cidades e economia. Contudo, esta nova política ainda procurava manter a flexibilidade nuclear de alvos para respostas a diferentes provocações; a estabilidade de crises, para que eliminasse a possibilidade dos soviéticos buscarem um primeiro ataque surpresa; e a igualdade percebida, ou seja, um equilíbrio de capacidades para prevenir uma coerção ou intimidação dos EUA e seus aliados. Esta política foi seguida pela busca da Deténte, através da assinatura de acordos como o Tratado de Redução de Armas Estratégicas ${ }^{8}$ (SALT 1, em inglês), a Convenção de Armas Biológicas (BWC, em inglês), e o Tratado de Mísseis Antibalísticos ${ }^{9}$ (ABMT, em inglês).

Do ponto de vista convencional, Nixon buscou reafirmar um compromisso americano e modificar outro. Com a retirada das forças do Vietnã, o exército americano foi diminuído em $50 \%$, mas isto possibilitou a reafirmação americana em relação à Europa com a recomposição das tropas na OTAN, que tinham sido despojadas de tropas e equipamentos para aquele conflito. Por outro lado, ele procurou relativizar o compromisso americano em lutar guerras locais em países em desenvolvimento, dando origem à Doutrina Nixon, baseada no primeiro princípio, o da autoajuda, ou seja, que o país ameaçado deveria ter responsabilidade por sua própria segurança; sendo o segundo princípio, da responsabilidade regional, com os países vizinhos ao conflito teriam que participar da sua solução; e o terceiro princípio, a responsabilidade residual americana, que proveria assistência militar, mas só interviria se houvesse um interesse vital americano sendo ameaçado, princípios que ficaram conhecidos como a doutrina de uma guerra e meia, de lutar um grande conflito na Europa e um menor em outra região. Esta estratégia foi mantida durante o curto governo Ford.

Quando o presidente Jimmy Carter (1977-1981) assumiu a presidência, a opinião pública em geral tinha uma percepção negativa da utilidade do uso militar como instrumento de política externa, devido principalmente às Guerras da Coréia e do Vietnã (Jordan et al, 2009). Com a crise econômica da década de 1970, principalmente pela recessão de 1974-75, a prioridade definitivamente se voltou para assuntos internos, levando o novo 
presidente a buscar a redução de gastos militares e, consequentemente, uma revisão da política de Segurança Nacional.

Apesar da realidade da equivalência estratégica, a introdução dos MIRVs, mísseis de cruzeiro e capacidades antissatélites, fez Carter se afastar da Suficiência Estratégica de Nixon e definir a Equivalência Essencia ${ }^{10}$ como nova diretriz nuclear, mas sem abandonar a lógica da MAD. Por isto que sua administração deu tanta ênfase na negociação e assinatura do SALT II ${ }^{11}$ - mas que não foi ratificado -, a fim de conseguir um limite máximo de ogivas para cada lado.

Por outro lado, houve a manutenção da estratégia de uma e meia guerra, sendo que, com o tempo, ficou cada vez mais certo que este segundo conflito seria na região do Golfo Pérsico. Já no final do seu mandato, diante de tantos ganhos soviéticos, o presidente Carter autorizou um plano quinquenal de aumento de gastos militares, que foram essenciais para as mudanças implementadas pelo seu sucessor.

Com a chegada ao poder de Ronald Wilson Reagan (1981-1989), houve uma mudança radical no discurso político e estratégia militar. Com um discurso de levar o Marxismo-Leninismo para "o monte de cinzas da história" (Jordan et al, 2009: 84), Reagan propôs um enfrentamento global do comunismo e um grande rearmamento das forças armadas americanas, política que ficou conhecida como Reestabelecer o Equilíbrio Militar e Reforma.

Aproveitando o início dado pela administração Carter, foi possível desenvolver e dispor rapidamente para as tropas novos equipamentos. Dentre vários, ficaram mais conhecidos o caça F-117 e B-2, os mísseis MX Peaceking, Pershing II, Trident e Tomahawk, os veículos de combate M-1 Abrams e Bradley, o helicóptero de ataque Apache, e o objetivo de ter uma marinha de 600 navios. Isto fez com que o orçamento militar, entre os anos de 1980 e 1985 , mais que dobrassem, passando de U\$ 142 bilhões para U\$ 286 bilhões (Bowman, 2004). Contudo, o maior projeto da administração Reagan foi a Iniciativa de Defesa Estratégica (SDI, em inglês), anunciada em março de 1983, como um sistema de lasers baseados em terra e no espaço, que dariam a capacidade aos Estados Unidos de se defenderem, e a seus aliados, de um ataque de mísseis balísticos intercontinentais, o que alteraria completamente a lógica da confrontação entre os dois inimigos (Jordan et al, 2009).

A segunda grande transformação que as políticas para a área militar americana sofreu veio com o Goldwater-Nichols Departmente of Defense Reorganization Act of 1986 (GNA, em inglês) que levou a uma mudança 
profunda nas forças armadas americanas. A intenção deste ato Congressual foi tentar superar problemas na organização das forças armadas que não haviam sido eliminados com o National Security Act de 1947, principalmente no que se referia às rivalidades inter-forças, definição e alocação de orçamento, desenvolvimento de equipamentos e no planejamento e execução de operações militares, que ficaram evidentes na guerra do Vietnã, na tentativa de resgate dos reféns da embaixada americana no Irã em 1980 e na invasão de Granada em 1983 (Stewart, 2005). Segundo o GNA, ficou estabelecido que o presidente teria que enviar anualmente, junto com o projeto de orçamento do próximo ano fiscal, um relatório ao Congresso, no qual deveria estabelecer qual seria a Estratégia de Segurança Nacional ${ }^{12}$ dos Estados Unidos.

Segundo Snider (1992 e 1995), que trabalhou na elaboração das primeiras NSS, houve uma grande dificuldade dos primeiros presidentes a passar por este processo. Ele aponta que a primeira NSS de Ronald Reagan foi preparada em um período curto de tempo e refletia o pensamento estratégico da época, com enfoque em um governo de gabinete e forte ênfase nos instrumentos militar de Poder, quase a excluir os outros. Já na segunda NSS de Reagan há duas mudanças, a primeira dando ênfase em todos os elementos de Poder de uma forma integrada, particularmente o econômico, e a segunda, que foi apresentar estratégias separadas para cada região do mundo, também com a integração dos elementos de Poder.

Ainda segundo Snider (1992 e 1995), para o governo de George H. Bush (1989-1993), foi muito complicado conseguir atender à demanda do GNA. Diante das rápidas transformações que tomaram forma a partir de 1988, acabaram tornando obsoleto o documento que estava preparado no início de 1989, e, assim, este acabou não sendo publicado. Já o documento do ano seguinte buscou abarcar, de forma cuidadosa, estas mudanças na União Soviética e, especialmente, na Europa Oriental, fazendo a apresentação de novas tendências que não apareciam anteriormente devido à preocupação com a confrontação termonuclear da Guerra Fria. Contudo, a administração acabou sendo atropelada novamente pelos acontecimentos de 1991, como a invasão do Kuwait pelo Iraque e a tentativa de golpe de Estado que levou à dissolução da União Soviética. Consequentemente, as atenções foram voltadas para essas demandas, fazendo o governo novamente a não publicar a NSS. A última estratégia quase foi pelo mesmo caminho, já que uma versão do documento estava preparada no início de 1992, mas a pressão da campanha presidencial, focada quase exclusivamen- 
te na economia doméstica, tornou politicamente complicada a apresentação de um documento em matéria de Segurança Nacional. Por tudo isto, ela foi publicada somente em janeiro de 1993, dias antes da posse do novo presidente democrata, William Jefferson Clinton (1993-2001), mais com a intenção de deixar registradas as realizações do passado do que um olhar para o futuro, além de deixar certos padrões pelo qual o novo governo seria avaliado. Por isto que, na apresentação desse documento, o então secretario de defesa Richard Cheney, como o então chefe do estado-maior conjunto, general Colin Powell, compareceram ao Senado americano e procuraram dar a dimensão do dividendo da paz com o fim da Guerra Fria.

Assim, a proposta foi a redução de $25 \%$ do orçamento militar em um programa de vários anos, que implicaria: para o exército, a redução de 18 para 12 divisões na ativa; para a força aérea, a redução de 36 para 26 alas aéreas de caças; para a marinha, a redução de 546 para 451 navios. Haveria ainda o cancelamento de 100 programas de desenvolvimento de novas armas, o fechamento ou realocação de 200 bases e instalações no mundo todo. Essa nova estratégia foi denominada defense build-down, com a mudança de contenção do comunismo e agressão soviética para uma estratégia mais flexível (Jordan et al, 2009).

\section{CONCLUSÃO}

Como discutido, há uma compreensão no Brasil, por parte de alguns, que política de defesa seria uma política de Estado, e não de governo, ou seja, que esta não poderia sofrer modificações ao longo do tempo pelos novos governantes, tendo em vista que esta tem, por objetivo último, a existência do Estado em um sistema anárquico. Apesar da preponderância realista ou neorrealista em Relações Internacionais embasar análises de política de defesa neste sentido, seria admitir que as decisões tomadas nesta área seriam baseadas somente nos aspectos externos, ou seja, a configuração de poder de cada Estado ou do conjunto do sistema internacional. Portanto, a realidade da dinâmica política interna aos Estados não seria levada em consideração.

Há, contudo, uma série de autores que apontam para fatores internos aos Estados como fundamentais para a elaboração de políticas setoriais por parte dos governos, principalmente no setor de defesa, como Kolodziej e Harhavy (1982), Buzan (1991) e Allison e Zelikow (1999), Proença Jr. e Diniz (1998) e Rudzit e Nogami (2010).

Outro argumento contrário à visão tradicional, e fundamental para 
países democráticos, é justamente a lógica da democracia. Como afirma Zagorski (1992), a moderna teoria democrática dá a fórmula para se estabelecer o controle civil sobre os meios militares e outros setores, ou seja, um único chefe executivo controla a máquina burocrática governamental, o qual, por sua vez, é governado por normas legais e burocráticas. Assim, cabe ao chefe executivo designar os objetivos políticos e aos seus auxiliares, os ministros, elaborar as politicas, enquanto à burocracia - tanto civil quanto militar - é suposta a execução ou administração das mesmas para se alcançar tais objetivos. Ou, no que Cottey, Edmunds e Forster (2002) denominam de governança democrática do setor militar via aceitação de ambas as partes, que esta é a melhor maneira de reger os assuntos da área, via governo democraticamente eleito.

Para explicitar melhor a lógica democrática, a diferenciação que Couto e Arantes (2006) fazem entre polity, politics e policy, é fundamental para a compreensão do que são as políticas públicas. Ou seja, o resultado do jogo político disputado (polity) leva ao candidato eleito ter a legitimidade de fazer a sua interpretação do interesse nacional, e esta se transformar em uma política pública setorial (policy). Portanto, os líderes eleitos têm o direito e o poder para modificar políticas anteriormente estabelecidas, dentre elas, a política de defesa. Na mesma linha, Proença Jr. e Diniz (1998) apontaram o que seria uma política de defesa.

A fim de exemplificar tal concepção, usou-se as mudanças implementadas pelos seguidos governos americanos durante a Guerra Fria. Buscou-se este exemplo uma vez que havia uma clara definição do que seria o maior objetivo do país e da sociedade, pela interferência do Executivo e do Legislativo na definição das políticas de defesa, demonstrando o controle civil sobre os meios militares, e, por fim, de nunca haver sido abandonada a maior preocupação de sobrevivência do Estado. Verificou-se que houve mudanças estruturais na forma de organizar as forças armadas americanas no período.

Assim, apesar da importância da área militar na Guerra Fria, a política deste setor não era considerada de Estado, mas, sim, mais uma politica governamental, na qual os objetivos políticos do líder eleito também se refletiam.

A administração Truman foi a responsável, diante da nova realidade pós-Segunda Guerra e emergência do confronto com a União Soviética, por empreender a maior reformulação da história militar americana. Neste momento é que se estabeleceu que a política da Contenção seria total e 
global, levando a estrutura militar americana em tempos de paz, e, consequentemente, o seu orçamento, a um tamanho nunca antes implementado.

Contudo, o como fazer isto, ou seja, os objetivos militares e a forma de organização das forças armadas, foram sendo modificadas conforme as conjunturas internas e externas mudavam, passando pela Retaliação Maciça de Eisenhower. Depois, as administrações Kennedy-Johnson mudaram para a Resposta Flexível, que se transformou na Suficiência Estratégica durante o período Nixon-Ford, passando para a Equivalência Essencial de Carter, e chegando na de Reestabelecer o Equilíbrio Militar e Reforma de Reagan. Com o rápido desmoronamento da União Soviética e o fim da Guerra Fria, veio na administração George H. Bush a estratégia defense build-down, que refletia o novo quadro internacional, assim como a realidade político-econômica e social dos Estados Unidos.

Portanto, diante tanto do referencial teórico sobre segurança e de relações civis-militares em democracias, quanto pela realidade das mudanças ocorridas nas políticas militares durante a Guerra Fria pelos diferentes presidentes norte-americanos, pode-se dizer que a política de defesa é uma política de governo, e que esta pode e deve ser modificada pela liderança política eleita diante das realidades internas e externas de cada país. Caso contrário, é admitir o insulamento burocrático militar e colocar este setor acima do governo eleito. 
RBED, v. 2, no 1, jan./jun. 2015

\section{NOTAS}

1. Após a Revolução Gloriosa (1688-98), foi instituída a legislação chamada Bill of Rights pelo Parlamento inglês, que, dentre alguns temas, limitou os poderes do rei e estabeleceu os direitos do Parlamento. Assim, em 1698, o Parlamento estabeleceu o Mutiny Act, que previa punições para militares pelos atos de deserção, motim ou sedição, mesmo em tempos de paz, medidas que anteriormente só poderiam ser tomadas em campo de batalha. Como a Biil of Rights proibia a existência de um exército em tempos de paz sem o consentimento do Parlamento, a aprovação anual da legislação anti-motim se transformou na forma de aprovação e controle das forças armadas pelos legisladores.

2. Gestapo é a sigla para Geheime Staatspolizei, ou seja, Polícia Secreta do Estado em alemão. Foi o seu caráter secreto e de espionagem na própria população alemã na construção do Nazismo, gerou uma suspeição muito grande nos legisladores americanos que algo parecido pudesse ocorrer nos EUA.

3. A primeira edição foi publicada em 1972.

4. A OTAN nunca chegou perto deste plano inicial, sendo o número total de divisões no início dos anos 1950 de 25 na ativa e 25 na reserva, sendo que, em meados dos anos 1960, chegou-se a ter 27 divisões na ativa e 30 da reserva, tendo um leve declínio para 23 divisões ativas (mais duas francesas que estavam fora da estrutura militar na OTAN) em meados da década de 1970, quantidade que voltou para aproximadamente 25 divisões na década de 1980 com o aumento de 14 para 16 divisões no exército americano durante o governo Reagan.

5. Second strike, em inglês

6. Strategic Sufficiency, em inglês

7. Assured destruction, também, mais conhecida como Mutual Assured Destruction, (MAD), em inglês.

8. Este acordo limitou o número de mísseis lançadores intercontinentais nos níveis existentes. Dentre as limitações, estava previsto que novos SLBM, que dão a capacidade retaliatória, somente poderiam ser introduzidos quando o mesmo número de antigos ICBMs ou SLBMs tivessem sido desmantelados.

9. A proposta para a criação do tratado ABMT se deu devido a dois princípios.

O primeiro era que, com a introdução da tecnologia das Múltiplos Veículos Independentes de Reentrada (MIRV, em inglês) poderia-se anular qualquer capacidade antibalística; e o segundo princípio era a percepção que o 
desenvolvimento de defesas antibalísticas poderia provocar uma corrida armamentista e levar a um primeiro ataque pelo governo que sentisse que não estivesse implementando no tempo adequado esta nova capacidade. Em 1972, ficou estabelecido que cada lado poderia ter somente dois sistemas, um para defender a capital e outro para os silos dos ICBMs.

10. Apesar de usar esta definição, o seu real valor para a estruturação das forças nucleares americanas foi muito questionada, como pode ser observado no artigo de Betts (1981).

11. Este tratado propôs a limitação da construção de ogivas nucleares, assim como a redução dos veículos de entrega, em todas as categorias, ao total de 2.250, fato importante uma vez que uma nova geração de mísseis soviéticos (SS-17, SS18 e SS-19) tinham uma capacidade muito maior de MIRVs, o que poderia tornar obsoleto o SALT I.

12. National Security Strategy (NSS, em inglês). 
RBED, v. 2, no 1 , jan./jun. 2015

\section{POLÍTICA DE DEFESA É UMA POLÍTICA DE GOVERNO}

\section{RESUMO}

O artigo traz os argumentos se política de defesa seria política de Estado ou de governo. Apresenta argumentos sobre relações civis-militares e diferenciação de conceitos em política. Usa as mudanças nas políticas militares nos EUA na Guerra Fria como exemplo. Conclui que política de defesa é política de governo.

Palavras-chave: Política de defesa, política de governo, relações civil-militar, Estados Unidos.

\section{ABSTRACT}

The article presents arguments if defense policy is a state or government policy. The authors' argument on civil-military relations and differentiation of concepts in policy. It uses the changes in military policies in the US during the Cold War as an example. The article concludes that Defense policy is a governmental policy.

Keywords: Defense policy, government policy, civil-military relations, United States.

\section{REFERÊNCIAS}

Allison, Graham; Zelikow, Philip. (1999) Essence of Decision. Explaining the Cuban Missile Crisis (2 ed.) New York: Longman.

Alsina Júnior, João Paulo Soares. (2009) Política externa e poder militar no Brasil. Rio de Janeiro: Editora FGV.

Betts, Richard K. (1981) "Strategic Equivalence. What is it? How do we get it?". Air University Review, November-December 1981.

Bowman, Tom. (2004) "Reagan guided huge buildup in arms race." The Baltimore Sun, June 8, 2004. Disponível em: http://www.baltimoresun.com/news/bal-te. pentagon08juno8-story.html\#page=1. Acesso em: 03/02/2015. 
Buzan, Barry. (1991) People. States \& Fear. An agenda for international security studies in the post-Cold War era. Boulder, Colorado: Lynne Rienner Publishers.

Cambone, Stephen A. (1998) The National Security Act of 1947 - 26 July 1947. A New Structure for National Security Policy Planning. Washington, D.C.: CSIS.

Cottey, Andrew; Edmunds, Timothy; Forster, Anthony. (2002) "The Second Generation Problematic: Rethinking Democracy and Civil-Military Relations." Armed Forces E Society, v. 1, n. 29, p.31-56, fall/2002.

Couto, Cláudio Gonçalves; e Arantes, Rogério Bastos. (2006) "Constituição, Governo e Democracia no Brasil." Revista Brasileira de Ciências Sociais, V. 21, n. 61.

Jordan, Amos A.; Taylor, William J. Jr.; Meese, Michael J.; Nielsen, Suzanne C. (2009) American National Security. 6a edição, Baltimore, Maryland: The Johns Hopkins University Press.

Kohn, Richard H. (1975) Eagle and Sword: the federalists and the creation of the military establishment in America, 1783-1802. Nova Iorque: Free Press.

Kokodzwij, Edward A.; Harhavy, Roebrt E. (1982) Security Policies of Developing Countires. Lexington, Massachusetts, Toronto: Lexington Books.

Lima, Maria Regina Soares de (2000). "Instituições democráticas e política exterior." Contexto Internacional, v. 22, n. 2.

Mallinson, Allan. (2009) The Making of the British Army. Londres: Transworld Publishers.

Proença Jr., Domício; Diniz, Eugenio. (1998) Política de Defesa no Brasil: uma análise crítica. Brasília: Editora Universidade de Brasília.

Rocha, Antonio Jorge Ramalho da. (2014) "Defesa: Dissuasão, Indústria, Desenvolvimento e Projeção de Poder." Seminário Brasil no Mundo - Deveres e Responsabilidades. Câmara dos Deputados. Comissão de Relações Exteriores e de Defesa Nacional. Disponível em: http://www.camara.leg.br/internet/sitaqweb/ textoHTML.asp? etapa $=11 \&$ nuSessao $=1281 / 14 \&$ nuQuarto $=0 \&$ nuOrador $=0 \& \mathrm{n}$ uInsercao $=0 \& d$ t HorarioQuarto $=09: 30 \& s g F a s e S e s s a o=\&$ Data $=2 / 12 / 2014 \&$ txA pelido=RELAÇÕES\%20EXTERIORES\%20E\%20DE\%20DEFESA\%20NACIO NAL\&txFaseSessao $=$ Seminário\&txTipoSessao $=\& d$ tHoraQuarto=09:30\&txEta $\mathrm{pa}=$. Acesso em: 01/03/2015.

Rudzit, Gunther; Nogami, Otto. (2010) "Segurança Nacional e Defesa: conceitos básicos para análise.” Revista Brasileira de Política Internacional, v. 53, pp. 5-24. 
RBED, v. 2, no 1, jan./jun. 2015

Snider, Don M. (1992) The National Security Strategy: documenting Strategic Vision. Carlisle Barracks, PA: Strategic Studies Institute.

(1995) The National Security Strategy: documenting strategic vision. Second Edition. Carlisle Barracks, PA: Strategic Studies Institute. Disponível em: http://nssarchive.us/wp-content/uploads/2012/05/Snider.pdf. Acesso em: 09/01/21014.

Stewart, Richard W. (2005) "Chapter 12: Rebuilding the Army Vietnam to Desert Storm." In: Stewart, Richard W (Ed.). The United States Army in a Global Era, 1917-2003. American Military History, Vol. II. Washington: Center of Military History. United States Army. Disponível em: http://www.history.army. mil/books/AMH-V2/AMH\%20V2/chapter12.htm. Acesso em: 27/11/2013.

Zagorski, Paul W. (1992) Democracy vs. National Security. Civil-Military Relations in Latin America. Boulder, C.O. : Lynne Rienner Publishers. 